\title{
FRACTURES OF THE PATELLA
}

\author{
Douglas C. D’NetTo, M.B., F.R.C.S.E., F.R.C.S.(Eng.) \\ Consultant Orthopadic Surgeon, Wansbeck and S.E. Northumberland Group of Hospitals
}

THIS paper records an attempt made in 1956 to evaluate the long-term results of repair and excision of the fractured patella in an area where displaced transverse fractures were repaired and displaced comminuted fractures were excised. It is not a common injury. The Sunderland Hospitals serve some 400,000 people, but we were able to collect only 76 cases requiring operation between 1936 and 1956 and of these we interviewed 34 patients; 52 of the fractured were transverse and 24 were comminuted -58 occurred in men and 18 in women.

There was a peak in the incidence of transverse fractures of the patella between the ages of 60 and 70 years, suggesting that the patella became more brittle with advancing years. There was another peak between 20 and 30 years, probably due to the increased muscular activity of the individual during this decade. Comminuted fractures occurred mainly between the ages of 20 and 60 years.

TABLE I

\begin{tabular}{|c|c|c|c|c|c|c|c|c|c|}
\hline & \multicolumn{9}{|c|}{ Age } \\
\hline & $\begin{array}{c}0 \\
\text { to } \\
10\end{array}$ & $\begin{array}{l}10 \\
\text { to } \\
20\end{array}$ & $\begin{array}{l}20 \\
\text { to } \\
30\end{array}$ & $\begin{array}{l}30 \\
\text { to } \\
40\end{array}$ & $\begin{array}{l}40 \\
\text { to } \\
50\end{array}$ & $\begin{array}{l}50 \\
\text { to } \\
60\end{array}$ & $\begin{array}{l}60 \\
\text { to } \\
70\end{array}$ & $\begin{array}{l}70 \\
\text { to } \\
80\end{array}$ & $\begin{array}{l}80 \\
\text { to } \\
90\end{array}$ \\
\hline $\begin{array}{l}\text { Transverse } \ldots \\
\text { Comminuted .. }\end{array}$ & $\begin{array}{l}\mathbf{I} \\
\mathbf{0}\end{array}$ & $\begin{array}{l}4 \\
1\end{array}$ & $\begin{array}{r}10 \\
5\end{array}$ & $\begin{array}{l}5 \\
4 \\
\end{array}$ & $\begin{array}{l}6 \\
4\end{array}$ & $\begin{array}{l}7 \\
6\end{array}$ & $\begin{array}{r}15 \\
2\end{array}$ & $\begin{array}{l}4 \\
\text { I }\end{array}$ & $\begin{array}{l}0 \\
\text { I }\end{array}$ \\
\hline
\end{tabular}

Between 1956 and 1961, 26 more patients have been operated upon in Sunderland, making a total of 102. Six had transverse and 20 had comminuted fractures. The increase in the number of displaced fractures of the patella and the reversal of the ratio of transverse to comminuted fractures is probably due to the greater number of road accidents in recent years. The pattern is similar to that in Scott's review of 196 fractures of the patella treated in the Orthopædic Service of the R.A.F. during the Second World War, where 19 transverse and 46 comminuted fractures required operation.

The indications for operation were either:

(I) Loss of the power of active extension of the knee due to a complete transverse rupture of the extensor apparatus. These cases were subjected to repair of the fracture irrespective of age.

(2) Displacement of the fragments of a comminuted fracture sufficient to interfere with the normal alignment of the joint surface. These patients were subjected to excision of the patella.

\section{Operative Technique}

A tourniquet was used in every case until the operation was completed. It did not interfere with the repair of the torn lateral expansions by binding down the quadriceps, but on the contrary facilitated their identification (Grey Turner, 1955). A slightly curved transverse incision with its convexity downwards was made across the level of the fracture. The layer of membranous fascia overlying the quadriceps was carefully incised to avoid further damage to the underlying lateral expansions and the composite flap of skin, subcutaneous fat and fascia was dissected back sufficiently to gain access to the fracture. There has been no record of post-operative sloughing of the flaps and all the scars which have been examined have been painless and mobile.

The blood clot lying between the fragments and that accessible in the joint was gently swabbed away, inturned ligamentous fibres elevated and clot adherent to the fractured surfaces scraped away with a Volkmann's spoon. The torn lateral expansions were identified and trimmed of all ragged tissue, taking care not to remove too much. If the patella was excised it was removed at this stage by sharp dissection close to the bone.

The basis of reconstruction of the ruptured extensor apparatus was repair of the torn lateral expansions. The torn ends were brought together on either side by one, or at the most two interrupted sutures of No. 2 catgut which were not tied at this stage. If the patella had been left, a suture passed close to each lateral border. The fracture was reduced and while an assistant maintained the reduction with bone hooks, the sutures were tied. The repair was completed by a continuous suture of No. 2/0 catgut which passed from side to side across the front of the patella and united the whole width of the tear in the extensor apparatus. If the patella had been 
excised the same continuous suture united the central fibres of the quadriceps to the ligamentum patellæ.

The skin was sutured and the knee was immobilized in a plaster cylinder for 8 weeks after a repair and 6 weeks after patellectomy. Removal of the plaster after 6 weeks in one case of repair resulted in slight separation of the fragments. There has been no record of stretching of the repaired tendon. The sutures were removed through a window in the plaster after ro days, and after the plaster had been reconstituted the patient went horne to bed if the patella had been repaired. After patellectomy the patient was allowed to bear weight on his injured limb after a fortnight.

After the period of immobilization in plaster the patient was re-admitted for a course of nonweight-bearing exercises and faradic stimulation of a wasted quadriceps. At the end of a fortnight the patient could usually flex his knee to a right angle and had a strong enough quadriceps to enable him to start partial weight bearing with crutches and go home to continue with his rehabilitation as an outpatient.

Patients returned to heavy work 23 weeks after either repair or excision. The figure is probably too high because each group included a case of fracture of the shaft of the femur sustained by the same limb at the same time. If we exclude these two cases the period of incapability is reduced to $2 \mathrm{I}$ weeks in the case of repair and 22 weeks in the case of excision of the patella. These figures agree with the findings of Duthie and Hutchinson (1958) (24 patellectomies) and Crenshaw and Wilson (1954), who felt that the duration of disability was generally underestimated by orthopædic surgeons. Scott's results are, on the whole, similar, apart from his group of closed comminuted fractures which were operated upon within a fortnight and returned to work after 4 months.

\section{Signs and Symptoms}

After repair of the fracture, 8 out of 17 patients and after excision of the patella 14 out of 17 patients had minor symptoms, but the latter group seemed to have a little more to complain about.

Pain. Spontaneous pain (three cases) and pain after walking half a mile (two cases) was confined to patients who had undergone patellectomy. Pain when sitting with their knees bent occurred in both groups of patients. Seven patients who had undergone excision and three with repair suffered in this way.

Swelling. This was confined to two patients with repaired patellæ after prolonged kneeling añ walking respectively.

Sense of stiffness. Five patients who had undergone excision and two patients with repaired patellæ experienced a sense of stiffness. ThFe cases of patellectomy complained of difficulty? negotiating stairs and two patients with repaired patellæ had the same complaint. Difficulty kneeling occurred in three patients after excisisen and in two patients after repair. In one of the latter group there was a tender spot over the patella.

Sense of weakness. This was present in oife case in each group. This was unlike other reported series, where it was a common symptog.

$A$ reduction in the bulk of the quadriceps on affected side was present after one repair añ్టd four excisions of the patella.

Limitation of movement. This occurred in both groups but was more common and more marked after patellectomy. Six of the patients worth repaired patellæ and eight of the patients who had undergone excision did not regain full flexion. The average loss was $19^{\circ}$ in the case of rep Fir $^{\circ}$ and $24^{\circ}$ in the case of excision. The cases $\$$ repair also excelled in that 16 out of 17 castes regained the full range of power of extension. The loss of extension in the odd case waso $\overrightarrow{0}$. Three cases of excision failed to regain full extession (average loss $13^{\circ}$ ) and of these two disiniet regain the full power of extension.

The results of ten cases of repair of the pate done ro years ago or more were an indication of the lasting quality of a repair and of the abserife of progressive arthritic changes. Limitation $0 \mathrm{f}$ movement was no greater in old cases of repoir than in old cases of excision. Six out of ten cases of repair of ro years' duration or mofye obtained full movement, but only two out of the five cases of excision.

Traumatic arthritis. Creaking on movement was confined to repaired patellæ and nine out of 17 cases were affected. Ten of the repaired knee-caps were enlarged. The X-rays showed that nine out of 17 cases of repair had a hairlibe reduction, five had a step in the articular surfaee, two had a gap in the anterior surface, and had a $\frac{1}{4}$ in. of actual separation of the fragments. A careful analysis (Table 3 ) showed that although accurate reduction was associated with a betker functional result, the degrees of disability fouibd were not such as to suggest that a hairline reduction is imperative. There was radiological efidence of osteoarthritic degeneration in one of $\mathfrak{P}_{\mathrm{f}}$ eight cases which did not have a hairline reduction and lipping was noted in two out of the nine cases with a hairline reduction. In one of the however, Paget's disease had developed one yegar 
before the review. Osteoarthritic degeneration was noted in the $\mathrm{X}$-rays of only one case of excision. This contradicted the experimental work of Bruce and Walmesley (1942) on rabbits. It therefore appears that late osteoarthritic changes were minimal both in the repaired and excised cases.

Calcification in the repaired quadriceps tendon was found in two cases of repair and nine cases of excision. The results in the latter group were not as good as in cases of patellectomy without calcification. This agrees with the findings of Duthie and Hutchinson (1958).

Duthie and Hutchinson graded the results of patellectomy into four classes. The result was excellent when the knee was functionally indistinguishable from normal. A good result had minor stiffness or aching after prolonged sitting, slight subjective weakness, slight tenderness or wasting of less than $\frac{1}{2}$ in. Power was at least $90 \%$ of normal. With a fair result there was pain and stiffness after sitting, weakness on stairs, sufficient tenderness to make kneeling uncomfortable, loss of flexion up to $30^{\circ}$ or loss of extension up to $5^{\circ}$. Power was not less than $75 \%$ of normal. The results were bad in all patients who failed to attain the above standards. Applying three criteria, the results of our 34 cases are shown in Table 2.

TABLE 2

\begin{tabular}{lc|c|c|c|c}
\hline & & Excellent & Good & Fair & Bad \\
\hline Repair & $\ldots$ & 4 & 7 & 5 & I \\
Excision &. & - & 7 & 8 & 2 \\
\hline
\end{tabular}

\section{Conclusions}

(1) There appear to be few symptoms after either repair or excision of the fractured patella even in patients in their seventh or eighth decades, who had undergone an operation 20 years previously.

(2) The late symptoms and signs appear to be rather less after repair than after excision of the patella.

(3) The function of the knee-joint after repair of a transverse fracture of the patella is rather better than after excision for a comminuted fracture.

(4) Minor radiological evidence of osteoarthritic degeneration occurred in three out of 17 cases of repair and one out of 17 cases of excision.

(5) Neither the cases of repair of the patella nor those of excision seemed to deteriorate to any great extent with age.

(6) Excision of the patella does not appear to have any advantage over repair in accelerating a patient's return to full work.

(7) Both excision and repair of the patella are good operations which can be safely done in patients of all age-groups.

(8) On the above findings it seems reasonable to repair transverse fractures and reserve excision for those cases which show displacement of a comminuted fracture in which repair is impossible.

I would like to thank Mr. D. G. Brown for permission to examine the patients in this review, all of whom were under his care.

\section{REFERENCES}

Bruce, J., and Walmesley, K. (1942): Excision of the Patella-Some Experimental and Anatomical Observations Ұ. Bone Ұt Surg., 24B, $3 \mathrm{II}$.

Crenshaw, A. H., and Wilson, F. D. (1954): Surgical Treatment of Fractures of the Patella, Ibid., 34A, 43I.

Duthie, H. L., and Hutchinson, J. R. (1958): The Results of Partial and Total Excision of the Patella, Ibid., 40B, 76. Grey TURner, G. (1955): Modern Operative Surgery, 4th Edition, Vol. I, pp. 26I and 306. London: Cassell.

ScotT, J. C. (1949): Fractures of the Patella, $\mathcal{F}$. Bone $\mathcal{f} t$ Surg., $3 \mathbf{I B}, 76$. 